\title{
History of Economic Thought at the University of Western Australia: 1953 compared to 2003
}

\author{
Michael McLure*
}

\begin{abstract}
This brief paper contrasts the history of economic thought programs offered at the University of Western Australia in 1953 and 2003: an interval of fifty years. The study identifies lessons for current HET units from Merab Harris' class of '53, where HET was taught with general reference to economic history. The contrast is also used as a basis for identifying the advantages and disadvantages of teaching HET collectively, as a topic within a compulsory core economics unit as it was in 1953, or independently, as an optional but specialist unit as it was in 2003. The paper concludes with some personal views on the future of HET studies.
\end{abstract}

\section{Introduction}

Prior to her retirement in 2006 as Associate Professor of Economics at the University of Western Australia (UWA), Pamela Statham-Drew went through the papers she had collected over her academic life. In the process, she found a partial copy of the 1953 UWA lecture notes and tutorial handouts prepared by 'Dr M. Harris' on the history of economic thought (HET). Fifty years after Merab Harris presented her lectures on HET, I lectured and tutored in the same field at UWA with my colleague, and former teacher, Dr Robin Ghosh.

The purpose of this brief paper is to reflect on how the context and content of classes in HET have changed at UWA from the snap shot provided by Harris' 1953 notes with the 2003 class in the History of Economic Analysis. Particular attention is given to the question of whether there are any lessons for us today from the class of '53. While issues relating to the learning environment and teaching methods are important, there is very little information available from which a sound assessment can be made on such matters. As such, the objectives, context and content of HET units in 1953 and 2003 are of prime importance.

This paper is in four main parts. Firstly, the context in which HET was taught at UWA in 1953 and 2003 is very briefly overviewed. Second, the objectives and the content of the 1953 and 2003 approaches to HET studies are compared and contrasted. Particular attention is given the relationship between the history of economic thought, as a history of ideas, and economic history, as a history of economic activities, in each of these two approaches. Third, the list of benefits derived from HET studies developed by Ian Kerr is used to assess the relative merits of each approach in order to establish whether the Class of '53 provides any lessons for current economics education at university. The fundamental issue in this regard is

\footnotetext{
* I would like to thank Robin Ghosh, Margaret Giles, Ian Kerr, Gregory Moore and Rod O’Donnell for their suggestions and/or comments. I would also like to thank Pamela Stathem-Drew for providing Merab Harris' notes to me and Reginald Appleyard, Selwyn Cornish, Neil De Marchi Ray Petridis and Malcolm Treadgold for their recollections of Harris' classes.
} 
whether the history of economic thought should be studied independently, as an optional but specialist (sub-disciplinary) unit, or collectively, as a topic within compulsory core units in economics.

The paper concludes with the observation that, ideally, some broad general elements of the history of economics should be included in mid-level undergraduate degrees, such as in 'core' second year microeconomic and macroeconomic units, and, at least one specialist but elective HET unit should also be offered to students in the final year of their undergraduate degree or those enrolled at honours/masters level. However, given the current level of student demand for studies in this field, the best practical outcome for the future of our sub-discipline at UWA specifically, and possibly Australia more generally, appears to be the simple maintenance of elective but specialist HET units within economics programs. If the viability of such units is threatened by low enrolments, only then should the alternative of incorporating HET within 'core' economics be seriously considered, as introducing such a significant change to syllabus would encounter many obstacles.

\section{The Context of the 'History of Economic Thought' at UWA}

The University of Western Australia was established by statute in 1911, with undergraduate classes commencing in 1913. Economics was taught within the 'Department of History and Economics' under the direction of the Edward Shann, the University's foundation Professor of History and Economics. However, the union of these two related disciplines within one department was not to endure and a distinct Department of Economics was eventually established in 1931, with Shann's title formally changing to Professor of Economics (Alexander 1963, p. 155). Even though responsibility for teaching economic history went to the new Department of Economics, and, indeed, has remained a subject within the economics discipline to this day, the change marked the first tentative step towards the diminution in the association between economics and its sibling disciplines in the social sciences.

Shann formally left UWA in 1934 and was succeeded by Alan Fisher in 1936, but his appointment only lasted two years and he was not replaced until 1941 when Frank Mauldon was appointed Professor of Economics. ${ }^{1}$ These delays in appointment did not help the development of economics at the University (Treloar 1988, p. 263). Nevertheless, while under Mauldon's leadership the foundations were laid for economics to be developed and eventually become grouped with other commercial subjects, initially through the establishment of the Faculty of Economics in $1954 .^{2}$ Merab Harris's 1953 lectures on HET where presented when economics at UWA was under Mauldon's chairmanship. She had already completed a doctorate at the University of London, with a dissertation on British Migration to Western Australia, 1829-1850 (Harris 1933), and her appointment at UWA was primarily on the basis of her achievements as an economic historian. Her subsequent involvement in the HET

\footnotetext{
${ }^{1}$ The A Biographical Dictionary of Australian and New Zealand Economists (King 2007) includes useful biographical entries on Shann (Snooks 2007), Fisher (Hogan 2007) and Mauldon (2007).

${ }^{2}$ This trend continued and eventually culminated in the establishment of the Faculty of Economics and Commerce (under the leadership of economics Ian Bowen) and the consequent establishment of a chair in Commerce. H. F Lydell was appointed as the Faculty's first Professor of Commerce in 1961. The formation of the Faculty of Economics and the Faculty of Economics and Commerce at UWA is reviewed in The Campus at Crawley (Alexander 1963).
} 
program was, therefore, not a result of scholarship in the field, but rather a result of endeavours to ensure that she had a full teaching load. Throughout her career, Harris' research remained entirely within the field of economic history, culminating in the publication of her scholarly biography: The Chief: C. Y. O’Connor (Tauman 1978). ${ }^{3}$

Unfortunately, there is very limited information available from which a sound assessment of Harris's approach to HET education can be made, although glimpses and hints can be gleamed from the recollections of some of Harris' former students from the late 1950s and early 1960s. One such student, Reginald Appleyard (Professor Emeritus, UWA) recalls Harris as a 'dour' teacher, although outside class she was pleasant and friendly person ${ }^{4}$. This view was endorsed by another ex-student, Selwyn Cornish (Australian National University), although he also remembers her with much affection, especially because she mentored his academic activities so effectively, both within the class room and as her part-time research assistant during two summer vacations. ${ }^{5}$ Ray Petridis (University of Notre Dame, Australia) recalls that Harris did not display much enthusiasm for HET in her classes. She would briefly introduce the topic of a lecture and then proceed to read from the pile of original books that she brought into class with her and without making much comment on what she had read. Her exam questions on HET also relied on students commenting on quotes, which appear to have been used effectively. ${ }^{6}$ Neil De Marchi's (Duke University) recollection is similar: he saw Harris’ lectures as unexciting and obscure, lacking in topical or problem-based foundation, and depending significantly on the piles of old texts that she read to class. ${ }^{7}$ While certain that his own passion for HET had nothing to do with what Harris actually taught, De Marchi nevertheless speculated that the source of this passion may actually be related to Harris' 'clear love of old text'.

In fairness to the memory of Harris's reputation as a teacher, it should be noted that her ex-students were asked to recall their student experiences in her secondary field of teaching - HET. Cornish, whose memory of Harris the teacher is most favourable, was also a student in Harris' economic history classes and his exposure to Harris was for a longer period than was the case for De Marchi and Pedridis. Moreover, while recollections such as those above are very interesting, they are limited by their partial character. Recollections differ between ex-students ${ }^{8}$ and contact was only made with students who subsequently become academics. In view of this, the focus on HET in 1953 in this paper is limited to Harris' written lecture notes.

\footnotetext{
${ }^{3}$ This book was published under her married name 'Tauman'. In the acknowledgements, she 'pays tribute' to Edward Shann for stimulating her interest in O'Connor and preparing the way for her to access original sources. As Shann died in 1935, and the book was published in 1978, it is clear that the gestation period for this detailed and insightful work spanned her entire academic career. Interestingly, Shann's successor, Alan Fisher, was also acknowledged in this book for 'opening doors' in New Zealand, where O’Connor initially migrated to from Ireland in 1865.

${ }^{4}$ Malcolm Treadgold (currently at the University of New England) was a student at UWA in the early 1960s but he was not taught by Harris, but he too recalls that she was pleasant outside class.

${ }^{5}$ Selwyn Cornish even indicated that it is unlikely that he would have pursued an academic career without the support and guidance that Harris gave to him.

${ }^{6}$ There were six HET questions in the 1953 exam, which is reproduced in the Appendix. Interestingly, only one of the six question did not require students to comment on a quote.

${ }^{7}$ De Marchi also recalled that younger students saw Harris to be something of 'a strange figure' who always dressed in long, flowing dress as if she had just 'stepped out of the Victorian era'.

${ }^{8}$ Although, in this case, the facts pertaining to Harris' use of old texts do not appear to be in dispute.
} 
By 2003, the economics program at UWA had changed significantly from that which prevailed fifty years earlier. Economics no longer dominated the curriculum of studies pertaining to economic activities and public policy. Commercial / business oriented subjects had also become prominent, with economics one of several discipline groups within the Faculty of Economics and Commerce, which interacted with the public as the 'UWA Business School'. The Head of Economics, Professor Ken Clements in 2003, was one of eight discipline heads (accounting and finance, management, marketing etc) within the Business School. The context within which the history of economic thought was taught had also changed. The change has been most dramatic in two important respects. First, in 1953 units were taught over a full academic year, whereas in 2003 they were offered on a semester basis. Second, in 1953 the history of economic thought was taught as a topic in the core 'Economics II' course, whereas in 2003 this field of study was taught as a specialised unit. Specifically, it is currently taught jointly as a third year undergraduate unit, 'History of Economic Analysis 310', which is offered concurrently with the postgraduate unit, 'Topics in the History of Economic Analysis 507'. The latter is offered as part of the master of economics program, although it is also frequently taken by honours students who have not taken 'History of Economic Analysis 310' during the third year of their degree.

Clearly the replacement of academic year units with semester units increased the capacity of economics programs to offer a greater range of specialised units. The fundamental issue to consider in this presentation is whether HET should continue to be taught as a specialist one semester unit, or revert to being taught as part of core economics. In view of the semester structure of economics programs, the latter option would probably have to involve a HET component in both microeconomics and macroeconomics.

\section{'History of Economic Thought' in 1953 and 2003}

In 1953 students of 'Economics II' were introduced to the topic of HET with the following words:

This section of the course in Economics II attempts to give a broad statement of the evolution of economic thought, concerning itself for the most part with the stream of development of English thought.

This section is designed to serve as an introduction to modern economic theory. It is no more than an outline. ... The treatment is based on the thesis that 'the economic structure of any given epoch and the changes which it undergoes are the legitimate determinants of economic thinking'.... Above all it is necessary to recognise that in the development of economic thought - as in any other phase of human experience - the process of change is continuously at work.

(Harris 1953a, p. 1)

The aims and the method are very clear and explicit from this statement. The topic is intended to provide:

(i) an overview of the field; and

(ii) a more profound understanding of modern thought by: 
(a) revealing the evolutionary character of economic thought; and

(b) highlighting the relationship between economic history (or the structure of economic epochs) and economic ideas during particular periods of economic history.

In 2003 however, the objective was to provide an in depth study of a few major developments in the history of economics. While it was anticipated that this would provide insight into contemporary theory, it was not done by plotting the historical path through which economics evolved into its current state. Rather, the emphasis was on the biographies of key theorists from particular periods and detail and controversies in their thought. While the relationship between economic history and history of economics was not ignored, it was given little prominence. Instead, greater emphasis is placed on thought and intellectual controversy.

\section{Content of the 1953 course}

The focus of this paper is dictated by the information contained in the available materials written by Harris from the 1953 class and an understanding of the general context of courses in economics at UWA at that time. The overview approach adopted by Harris (1953a, 1953b, and 1953c) covers five main epochs: mediaeval economic thought; mercantile thought; forerunners to classical economics, classicism; and neo-classicism (and Keynesian thought).

In keeping with the abovementioned approach, the treatment of mediaeval economic thought is undertaken by blending economic history with the history of economic thought. It commences with discussion of the dominant characteristics of mediaeval society: religion as the standard by which human activities and institutions are judged; the Church as the dominant institution; feudalism and class as a functional division of society; the notion of 'local particularism'; and a moderate element of universalism. Following this, there is discussion of the emergence of economic thought during this period, with primary reference to Thomas Aquinas. Issues in economic thought discussed range from: trade, the doctrine of 'just price' in its mediaeval expression, which is discussed and differentiated from the classical concept of 'normal value'; and money and interest, focusing on the condemnation of usury and the associated complexity.

The notes on mercantilism similarly blend economic history with the history of economic thought. Legislative impediments to economic activity (apprentices, navigation, agricultural protection) are discussed as the means of achieving the political end of nationalism. While the period is discussed in this context of nationalism, economic thought is characterised by Harris as a rather ad hoc development dealing with particular situations, and not an integrated body of knowledge. Moreover, the ideas of particular mercantilists are not discussed in this topic.

The lecture notes for the next topic, on the 'forerunners of the English Classical Economists', deals with William Petty (1628-1687), David Hume (17111776) and the Physiocrats. Again, the lectures commence by placing the conditions that lead to the emergence of classical political economy in the context of economic history:

The rate of change in industry in England in the eighteenth century was so marked as to appear revolutionary - the industrial revolution. Modern industrial capital 
development had its beginnings much earlier in the eighteenth century. Already in earlier centuries capital accumulation in trade was being directed to manufacturing, to mining and to agricultural development.

In the eighteenth century, however, the expansion of investment opportunities, the development of banking, the extension of industrial capital, changes in land ownership and in methods of husbandry, the growing power of the middle classes, increases in landless rural and urban wage-earning classes all contributed to changes in economic practice and modification of economic ideas.

(Harris 1953b, p. 9)

Unfortunately, the 1953 lecture notes on classical political economy have not survived, but the tutorial questions on this topic have (Harris 1953d and 1953e). It is evident from these that particular emphasis was given to value theory: 'Consider Adam Smith's theory of value', 'State concisely Ricardo's theory of value', “"Marx's theory of value is the Ricardian one” - Explain this statement and show how significant Marx's theory of value is in his theoretical model'. Clearly these core theoretical questions are not suggestive of the blend of economic history and history of economics in Harris' lecture notes for earlier topics. However, this does not necessarily mean that her lectures do not incorporate economic history with her discussion of Classicism as the lecture notes are not available and her introduction to 'the forerunners of English classical economics' is strongly suggestive of such an approach.

In the final topic, on 'Neo-Classicism', the importance of Jevons, Wicksell and Wicksteed, is noted and three schools of neoclassical thought are acknowledged (Austrian, Lausanne and Cambridge). Most of the discussion concerns the Cambridge school, with the greatest emphasis on Marshall, as the leader of that school's first generation. Nevertheless, consideration is also given to this school's second generation of theorists, with specific mention made of Pigou, Keynes, Robertson and Kalecki, and brief mention is also made to its third generation, with very brief references of Sraffa, Dobb, Robinson and Henderson, who Harris presented as economists reacting against neoclassical economics. Discussion of economic history is diminished in her notes on this section. Instead, there is discussion of the Marshallian and the Cambridge view of what economics deals with: namely, the need to provide good council to influence policy. That is, the practical relevance of partial equilibrium analysis to policy is emphasised. The same is true of the brief discussion on Keynes (although hand written notes indicate that the Keynes part of the course was much more extensive than the typed notes suggest), with mention of the rapid spread of his ideas and the New Deal in the USA. It should also be noted that this final topic concluded with an 'epilogue' devoted to alternative branches of thought within economics, making mention of the Historical school, the Institutional school and the 'mathematical' approach.

On balance, Merab Harris's course was generally true to her stated objectives. In particular, the HET section of the Economic II in 1953 was very broad ranging (from mediaeval to Keynesian economic thought), very general, and presented in a manner that combined economic history and economic thought to reveal the evolutionary character of economic thought. It can be said that the program used HET to contribute to an increase in students' critical understanding of modern economic thought, especially the limitations of such thought, by highlighting its 
evolutionary character and links to economic history. However, it did not, and was not intended, to provide insight into the detail of intellectual contributions or the context within which intellectual exchanges lead to the emergence of new ideas, which is of great interest to intellectual historians.

One obvious and significant weakness of the approach needs to be underlined. In attempting such a broad coverage of HET, parts of the treatment are superficial. Indeed, in the case of the more recent history pertaining to neoclassical thought, students were sometimes provided little more than a list of important scholars associated with a particular tradition, but with little attempt to outline what it was that those names contributed. While some information on this would no doubt have been presented verbally to students, it is unlikely to have been treated in any significant detail (otherwise, something on the issue would have been included in the written lecture notes).

\section{Content of the 2003 course}

Fifty years after Merab Harris delivered her program, the HET program at UWA had changed dramatically. As a result of teaching a specialist unit to a small number of students, the goals, and the associated teaching strategies, have changed significantly. The focus on breadth in the evolution of economic ideas evident from 1953 has been replaced by an approach that focuses on depth by investigating just two major developments in economic thought: the classical school of political economy and the Lausanne school.

The four week module of the Lausanne school dealt with the contributions of Walras and Pareto. Walras' contribution was placed in the context of the other founding marginalists (Jevons and Menger), his system of general equilibrium was discussed and the role of Tâtonnements in the equilibrating process debated. In addition, time was devoted to the perceived normative bias in both his methodology and pure economics, as was his position on scientific socialism. In regard to Pareto, his contributions to welfare theory, choice theory and ordinal utility were reviewed and his distinction between logical and non-logical (but not illogical) action was considered. Attention was also given to the development of his sociology, especially his sociological theory of welfare, which was contrasted with his better known economic theory of welfare that culminated in a complete outline of the first fundamental theorem of welfare economics and an incomplete statement of the second fundamental theorem.

The goal here was twofold. First, to review aspects of the Lausanne school's work that are most well-known to the economics profession and with which students would also have some vague familiarity: Walras on general equilibrium and Pareto on welfare and choice theory. This step is broadly consistent with Harris' general approach, although no time was allocated to the relationship between economic ideas and economic history. Second, aspects of Walras and Pareto's work were highlighted that both theorists regarded as fundamental to their specification of their scientific systems, but which the economics profession has since discarded. In the case of Walras, this included his attempt to integrate justice and economic theory and the role that he accorded to Tâtonnements in studying static and evolving systems. In the case of Pareto, consideration was given to his largely discarded distinctions between: ophelimity (benefits derived from hedonistic pleasure) and utility (benefits derived 
from 'useful' activities); economic and sociological maximisation; and the respective places of his theory of economic equilibrium and his theory of social equilibrium.

In the eight week module on classical political economy, attention was given to the major British theorists, including their biographical overviews. Adam Smith was discussed in great detail, with attention given to his reaction against mercantilism, his theory of growth, his theory of distribution and views on the role of the state. T. R. Malthus's theory of population was debated, as was Ricardo's reaction to this theory and Ricardo's theory of distribution. The section finished with discussion of J. S. Mill and his theory of growth and the principle of laissez faire in classical economics.

In comparison to the 1953 course, the 2003 course placed greater emphasis on: biography, detail of intellectual contributions; (including those aspects which the economics discipline did not subsequently develop), and debate over ideas. Notwithstanding this, the 1953 offers some potential lessons for how HET should be presented at university.

\section{Lessons from the Class of '53}

To consider the lessons from the class of ' 53 for the future classes at UWA, and perhaps other universities, in the history of economics, it is first useful to identify the benefits that students receive from studying HET. In this regard, Kerr (2002) has listed a range of potential benefits on 'the value of HET' which may be re-ordered and summarised as:

1. its intrinsic worth derived from the satisfaction of intellectual curiosity;

2. avoiding errors of the past;

3. extending the range of hypotheses because, while methods of analysis from the past may be redundant, the types of questions asked may still be relevant;

4. highlighting unfulfilled evolutionary potential of classic works because issues lost in the subsequent syntheses may still be relevant;

5. preserving alternative paradigms to maintain intellectual heritage, just as we attempt to preserve cultural heritage;

6. enriching understanding of the discipline by demonstrating the development of ideas;

7. offsetting neglected holism and highlighting the relevance of integrating systems; and

8. providing long-term perspective on the development of economics that transcends fads and fashion.

On the face of it, the benefits listed above which are less suited to HET being included in core economics units include points 1 to 5 inclusive. Satisfying intellectual curiosity implies that the intrinsic worth of HET primarily relates to 'consumption'. Core economics, while having unequivocal intrinsic benefits, seeks to add to human capital. That is, the investment element of core economics is emphasised. Avoiding error is obviously important, but this requires in depth investigation before the significance of such errors emerge and this is best serviced by 
a specialised course. Extending the range of hypotheses is also important, but more for research purposes than for leaning core economics. Research students would benefit the most and they would typically need the greater depth that a specialised unit provides. Similarly, an appreciation of the unfulfilled evolutionary potential of classic works serves the needs of researchers and students seeking a profound knowledge of intellectual history. These may best be provided by a mix of studying a specialised HET unit and undertaking research. Preserving alternative paradigms is a fundamental goal of HET, but again this goal has limited relevance to enhancing understanding of current theory. Its main relevance is in developing an understanding of intellectual history. This is more appropriately pursued in a specialised HET class.

However, points 6 to 8 inclusive are all outcomes that students of core economics would benefit from because they contribute to increasing students' critical understanding of modern economic thought, especially the limitations of such thought. Increasing understanding of the development of ideas reveals that economics is contingent upon the level of development of theory at the current date, that it is not valid in any absolute sense and that it will continue to evolve. Redressing neglected holism provides students with the opportunity to develop the capacity to synthesise information. This is a useful skill in core economics, where different schools of thought bring different perspectives to particular issues. Finally, enhancing the capacity to distinguish between fads (the economics of the new economy and globalism) and substantive developments which lead to progress in economic theory is important.

These outcomes would benefit students of core economics and complement the objectives of core economics. As such, they would appear suitable for inclusion in a core economics course along the lines presented in 1953. However, the outcomes would be achieved more effectively in a specialist class on HET because they generally relate to depth of understanding in the evolution of ideas which is more emphasised in a specialist that a core unit. In general terms, this implies that the arrangement in place in 2003 was more appropriate for teaching HET than those that prevailed in 1953 and will continue to be so. ${ }^{9}$ The main lesson from the UWA Class of '53 concerns the desirability of placing greater emphasis on the relationship between economic history and the history of economic thought.

However, a limitation of the above discussion is that it is partial. It implicitly assumes students either study core economics and a specialised HET unit, or core economics including a HET topic. Of course, students are free to choose, and universities like UWA that offer specialised HET units and core economics units with no HET content effectively provide students with the option of choosing to eliminate HET from the economics program. Unfortunately, this option is being exercised with great frequency as, in most instances, students complete their economics degree by completing core economics units but without electing to take a specialised HET unit. At UWA, only around 20 students enrolled in either masters, honours or $3^{\text {rd }}$ year economics study HET - just under $20 \%$ of all economics students enrolled at that level.

\footnotetext{
${ }^{9}$ Interestingly, in 1990 the University of New England offered a specialist HET unit that attempted to provide students with both breadth and depth concurrently, with one lecture per week devoted to overviewing the general development of economic theories and another lecture per week devoted to specified topics associated with the ‘big names’ of economics (Pullen 1990, pp. 36-40).
} 
Of course, it is possible that specialised HET enrolments across the Australian university sector will decline over time (at least if the anecdotal evidence of the decline in HET in the US university system provides an indication). The choice that universities face may change from: providing students with HET as either a topic in compulsory core economics courses or as an optional but specialist unit; to providing students with HET as a topic in compulsory core economics courses or not offering HET topics in the economics program. With this in mind, then the experience in presenting HET as part of Economic II at UWA in 1953 may be of some current relevance. In this context, the main the lessons from the Class of ' 53 relate to the integrating of HET back into core economics units (if specialist HET programs lose their viability). This could be done by incorporating a discrete HET topic (as in 1953) into core economics. Alternatively, it could be done by integrating HET issues into existing topics so that core economics would then be taught with due regard to the important historical moments in the development of particular economic ideas. In such circumstances the only aspects of HET incorporated, or integrated, into core economics would be those aspects that clarify or provide perspective on modern thought. This would, of course, require the active support of lecturers in charge of core economics units, which, based on my discussions with colleagues at the $12^{\text {th }}$ Australian Teaching Economics Conference at UWA in July 2006, may prove difficult to achieve

As a HET teacher, it is my hope that this does not come to pass. My clear preference is for the sub-discipline to continue to be taught as a specialist unit.

\section{Conclusion}

Of course, there are clear dangers in extrapolating lessons from UWA's experience with HET to other universities. The differing traditions that have developed within each university cannot be ignored.

For example, consider the University of Sydney, which has perhaps the greatest heritage in teaching and researching HET of any Australian University. In 1931, final year pass students and honours students at Sydney were completely occupied with the study of economic classics, and, in 1982, the optional HET program was still extensive, comprising: a wide-ranging three term (one year) unit from the Economics III program; and a more targeted classical political economy course which was also taught over three terms (one year) and taken by the majority of honours students as part of their Economics IV program (Groenewegen 1982, p.2). At the University of New England, HET has been through a somewhat cyclical pattern. Prior to 1975 it was 'quasi-compulsory', between 1975 and 1989 enrolments suffered as the one semester joint third year and honours year course took on a more clearly optional aspect and became actively discouraged at honours level, and then from in the first few year of the 1990s enrolments increased significantly following a change in the unit title, from 'History of Economic Thought', to 'The Development of Economic Theories and Policies’ (Pullen 1990).

The histories of HET at UWA, Sydney University and the University of New England are clearly very different, as are the current circumstances of both universities. At any given time, the lessons from UWA's experience with HET programs may well be different across the various universities. That said, I still think 
it is possible to make some broad observations which may have relevance to UWA and to other Australian universities. On an optimistic note, if student demand for HET topics does not decline, as feared, but rises, as hoped, what would be the ideal outcome? The answer, I believe, is that Australian universities would do a little of each: include some broad HET elements in core economics and offer optional HET classes. As some depth of economic knowledge is required for students to successfully complete a specialised HET unit, this should only be offered to final year undergraduates or to honours/postgraduate students. As less depth of economic knowledge is needed for broad HET review included as part of a core economics (or as a discrete topic in core economics), these units could be offered at a lower level, say second year.

Such an arrangement would appear to have two main benefits. Students who make the choice to study a specialised HET unit would be making a more informed decision, as they would have already been exposed to the subject in second year (i.e second year HET topic may become 'merit goods'). Second, HET would be reintegrated within the main stream, with some of the associated benefits for students identified by Ian Kerr.

To achieve this, teachers of HET may need to be active in attracting students. The University of New England's experience with changing the name of its HET unit is one option, although it should be noted that UWA's experience of changing the name of its HET unit from the 'History of Economic Analysis' to the 'History of Economic Ideas' in 2005 had no observable impact on student enrolments. Rod O'Donnell has also suggested to me that organising HET courses thematically, rather than by topics developed around major individual figures in economics, may attract more students. No doubt, other creative ways of attracting students could also be contemplated. Merab Harris' 1953 syllabus implies that blending economic history with HET has merit from a didactic perspective and this may also make the subject more attractive to potential students.

However, obstacles to the preservation of HET as an optional specialised subject are considerable. As already mentioned, against the trend, growth in enrolments in HET would be required. Just as importantly, teachers of core second year economics units would need the willingness and competence to teach economics in an historical manner by either setting a specific HET topic or integrating HET issues within the treatment of existing topics. How many second year lecturers have studied or undertaken research in this field? How many would be willing to alter their syllabus to integrate HET themes in existing topics or add a new HET topic? Nevertheless, these obstacles will need to be addressed if HET enrolments decline and universities are forced to decide between dropping HET from economics programs; or including it within the core economics program. If such a circumstance emerged at UWA, I would advocate the latter - the inclusion of HET within second year microeconomics and macroeconomics.

\section{Appendix}

University of W.A.

November 1953 
Section A (students were required to answer at least 2 questions from this section)

1) "The person whom medieval doctrine condemns is the debenture-holder, the man who eschews all risk, whose money is safe and who yet looks for a reward."

Explain this statement.

2) "Consumption is the sole end and purpose of all production and the interest of the producer ought to be attended to, only as far as it may be necessary for promoting that of the consumer ... But in the mercantile system, the interest of the consumer is almost constantly sacrificed to that of the producer" (Adam Smith: The Wealth of Nations).

Comment concisely on this statement, indicating: (a) Adam Smith's objective in economic inquiry; and (b) his views of the Mercantile System.

3) “The crux of Ricardo's theory was that increased population necessitated a resort to inferior lands, so that rents increased” (B. S. Keirstead: The Theory of Economic Change).

Discuss this claim.

4) Outline Marx's theory of economic development. What are its limitations?

5) "The utility theory was clearly the alternative to the cost theory ... but its elaboration was strangely delayed by the authority of the classical theory, and when at last the system of utility value was introduced it appeared revolutionary ... modern theory, far from revolutionizing classical teachings rather complements them by adding a neglected element”.

Discuss this statement of Heinmann. Give particular attention to one of the main contributors to the utility theory of value.

6) “The 'Economics of Welfare' is built around the concept of economic welfare of the community and the size and distribution of its national dividend, and is the leading modern example of the approach to economics adopted in the 'Wealth of Nations', and described more recently as the 'National Income' approach” (Hutchison).

Develop this idea.

\section{References}

Alexander, F. 1963. The Campus at Crawley: A Narrative and Critical Appreciation of the First Fifty Years of the University of Western Australia, Melbourne: F. W. Chesire (for UWA Press). 
Groenewegen, P. 1982. 'History of Economic Thought in the Faculty of Economics at Sydney University’, HETSA Newsletter, No 3, pp. 2-11.

Harris, M. 1933. British Migration to Western Australia, 1829-1850, PhD. Thesis: University of London.

Harris, M. 1953a. 'A Short Review of the History of Economic Thought', Unpublished University of Western Australia Lecture Notes, 1-8.

Harris, M. 1953b. 'The Forerunner of the English Classical Economics', Unpublished University of Western Australia Lecture Notes, 9-13.

Harris, M. 1953c. 'Neo-Classicism', Unpublished University of Western Australia Lecture Notes, 1-8.

Harris, M. 1953d. 'Tutorial Topics: Second Term', Unpublished University of Western Australia Tutorial Papers, 1.

Harris, M. 1953e. 'Tutorial Topics: Third Term', Unpublished University of Western Australia Tutorial Papers, 1-2.

(Harris) Tauman, M. 1978. The Chief: C. Y. O'Connor, 1843-1902, Perth: UWA Press.

Harris Tauman, M. 1988. 'O'Connor, Charles Yelverton (1843 - 1902)', Australian Dictionary of Biography, Vol. 11, Melbourne: Melbourne University Press, pp. 5154.

Hogan, W. 'Allan George Barnard Fisher (1895-1976)', in A Biographical Dictionary of Australian and New Zealand Economists, edited by John King, Cheltenham: Edward Elgar, pp. 99-102.

Kerr, I. 2002. 'The Value of the History of Economic Thought', Journal of Economic and Social Policy, 6(2), Winter, 2002, pp. 88-99.

King, J. 2007. A Biographical Dictionary of Australian and New Zealand Economists, Cheltenham: Edward Elgar.

Petridis, R. 'Frank Richard Edward Mauldon (1891-1961)', in A Biographical Dictionary of Australian and New Zealand Economists, edited by John King, Cheltenham: Edward Elgar, pp. 183-185.

Pullen, J. 1990. 'The Teaching of the History of Economic Thought at the University of New England', History of Economics Review, No.13, pp. 30-40.

Snooks, G. D. 'Edward Owen Giblin Shann (1884-1935)', in A Biographical Dictionary of Australian and New Zealand Economists, edited by John King, Cheltenham: Edward Elgar, pp. 247-250. 
Treloar, D. 1988. 'Economics and Commerce' in, Campus and the Community: the University of Western Australia 1963-1987, edited by Brian de Garis, Nedlands: UWA Press, pp. 263 - 280. 